\title{
Detection of Iron Wear in Mechanochemistry Using Magnetometry
}

\author{
M. BALÁZ̆ $\check{Z}^{a, *}$ M. RAJŇÁK $K^{b, c}, Z$ Z. ShalabAYEV ${ }^{d}$ AND A. ZUBRIK ${ }^{a}$ \\ ${ }^{a}$ Institute of Geotechnics, Slovak Academy of Sciences, Watsonova 45, 04001 Košice, Slovakia \\ ${ }^{b}$ Institute of Experimental Physics, Slovak Academy of Sciences, Watsonova 47, 04001 Košice, Slovakia \\ ${ }^{c}$ Faculty of Electrical Engineering and Informatics, Technical University of Košice, Letná 9, 04200 Košice, Slovakia \\ ${ }^{d}$ Al-Farabi Kazakh National University, al-Farabi ave. 71, 050040 Almaty, Kazakhstan
}

\begin{abstract}
Mechanochemistry is already established in various research fields. However, the production of unfavorable wear from milling media can adversely affect quality of obtained products. In the present study, the possibility to detect iron wear in trace amounts using magnetometry is shown. As a model, the novel mechanochemical synthesis of covellite/sulphur $(\mathrm{CuS} / \mathrm{S})$ composite from elemental precursors was realized. After 12.5 min of treatment, the peaks of $\mathrm{Cu}$ could no longer be identified in the X-ray diffraction pattern, whereas those of $\mathrm{CuS}$ and $\mathrm{S}$ were quite intensive. The kinetics of the process was evaluated by determining the amount of free sulphur. As both reactants and products are diamagnetic, possible magnetic response can be registered only due to wear from stainless steel milling chamber and balls. Magnetization increased with milling time, always showing the diamagnetic slope until 15 min of milling. After termination of the CuS formation, the wear production seems to be boosted. After $30 \mathrm{~min}$, the saturation magnetization of $0.166 \mathrm{~A} \mathrm{~m}^{2} / \mathrm{kg}$ corresponding to $0.76 \%$ of iron in the reaction mixture was detected. In general, magnetometry could be used for possible identification of trace amounts of wear in reactions performed using stainless steel media, which are most commonly used in mechanochemistry.
\end{abstract}

DOI: 10.12693/APhysPolA.137.684

PACS/topics: magnetometry, wear, iron, copper sulfide, composite, sulphur

\section{Introduction}

Mechanochemistry is an environmentally friendly method for the production of materials, due to its applicability in completely solid-state, solvent-free character and possibility to be performed at ambient conditions [1].

In mechanochemical synthesis, wear from milling media is a serious issue, as it can have a significant effect on the reaction progress, properties, and/or the applications of the produced materials [2,3]. Most often, the mechanochemical experiments are performed in a steel chamber [4]. Even a very small amount of iron can cause serious issues (e.g., the NMR spectra are impossible to be measured). On the other hand, the phenomenon of wear from milling bodies can be beneficial, e.g., for a breakdown of minerals or nanocomposites preparation [5]. The methods which are usually applied for the characterization of the products (e.g., powder X-ray diffraction, $\mathrm{XRD}$ ) are not very sensitive and the presence of wear can be overlooked, and its discovery in the application stage can be too late. Magnetometry is a very suitable method for this purpose, as already traces of iron are detected due to its ferromagnetism. However, it has not been used for this purpose until now. Its application in mechanochemistry has been limited to the investigation of reaction kinetics (e.g., in [6]).

As a model reaction of nanomaterial preparation, synthesis of copper sulfide, $\mathrm{CuS}$ from elemental precursors

*corresponding author; e-mail: balazm@saske.sk can be selected, as neither reactants or products exhibit magnetic behavior. Moreover, the produced material has interesting applications in various fields [7], which can be further boosted when it is part of the composite. Sulfur seems to be a good candidate to form a composite with $\mathrm{CuS}$, as has been already demonstrated in $[8,9]$. Moreover, sulphur particles alone are applied e.g., in lithiumion batteries [10]. The rapid mechanochemical synthesis of $\mathrm{CuS}$ has already established method [11], however, the mechanochemical approach has not been used for the preparation of $\mathrm{CuS} / \mathrm{S}$ composite until now.

The novelty of the present work is two-fold: (i) utilization of magnetometry for the investigation of iron wear, (ii) mechanochemical synthesis of $\mathrm{CuS} / \mathrm{S}$ composite. We have discovered that very small amounts of wear are detectable, which predetermines this approach to be used for investigation of a wide spectrum of mechanochemical reactions in future.

\section{Experimental}

Copper (Pometon, Italy) and sulphur (99\% CG-Chemikalien, Germany) were used without further purification. Ball milling procedure was realized in a Pulverisette 6 planetary ball mill (Fritsch, Germany) under the following conditions: $250 \mathrm{~mL}$ of steel milling chamber containing 50 steel balls with $10 \mathrm{~mm}$ diameter (overall weight of $178 \mathrm{~g}$ ), milling time from 2.5 to $30 \mathrm{~min}$, rotational speed $550 \mathrm{rpm}$ and air atmosphere. The mixture of reactants $(4 \mathrm{~g}$ altogether) consisted of $1.9908 \mathrm{~g}$ of copper and $2.0092 \mathrm{~g}$ of sulphur, according to the reaction below: 
$\mathrm{Cu}+2 \mathrm{~S} \rightarrow \mathrm{CuS} / \mathrm{S}$.

After milling, the powder was collected from the milling chamber. The residual powder present on the lid was not taken for analysis, as its participation in the milling process is questionable.

The XRD patterns were recorded by a D8 Advance diffractometer (Bruker, Germany) with $\mathrm{Cu} K_{\alpha}(40 \mathrm{kV}$, $40 \mathrm{~mA}$ ) radiation. XRD patterns were measured in the $2 \theta$ range $10-65^{\circ}$ with step size of $0.03^{\circ}$ and step time of $10 \mathrm{~s}$. For phase analysis, the JCPDS-PDF2 database and the Diffracplus EVA software (Bruker, Germany) have been used.

The content of non-reacted elemental sulphur in the samples was determined by a gravimetric method using a Soxhlet analysis employing $\mathrm{CS}_{2}(99.9 \%$, Fischer Chemical) as a solvent. After its evaporation, the percentage of non-reacted sulphur was calculated using the following equation:

$$
S[\%]=\frac{m_{f 1}-m_{f 0}}{m_{s 0}} \times 100,
$$

where $S[\%]$ is the content of non-reacted sulphur, $m_{s 0}$ is the starting amount of sulphur in the reaction mixture $(\mathrm{g}), m_{f 1}$ is mass of the flask after extraction $(\mathrm{g})$, and $m_{f 0}$ is mass of the flask before extraction $(\mathrm{g})$.

Overall sulphur content in the samples was determined using a Vario MACRO cube elemental analyser (Elementar Analysensysteme GmbH, Hanau, Germany) equipped with a thermal conductivity detector. The combustion and reduction tubes were set to 1150 and $850^{\circ} \mathrm{C}$, respectively. Sulphanilamide $(41.81 \% \mathrm{C}, 16.26 \% \mathrm{~N}, 4.65 \% \mathrm{H}$, and $18.62 \% \mathrm{~S}$ ) was used as a standard.

Magnetometry measurements were performed by using vibrating sample magnetometer (VSM) installed on a cryogen-free superconducting magnet (Cryogenic Limited, United Kingdom). The samples were measured in powder form packed in a specialized capsule. After the measurements, the magnetic moment values were divided by the sample mass, yielding the mass magnetization. The content of iron wear was calculated from the obtained data.

\section{Results and discussion}

The progress of the reaction can be seen well from the XRD patterns presented in Fig. 1. On the contrary to the study [11], the peaks of starting copper did not disappear within a second range in this case, but were still visible until $10 \mathrm{~min}$. As $\mathrm{Cu}$ peaks diminish, those of $\mathrm{CuS}$ become more intensive. After $12.5 \mathrm{~min}, \mathrm{Cu}$ could no longer be identified. Sulphur peaks are visible throughout the whole process, so they are involved in the composite structure with the as-synthesized $\mathrm{CuS}$ at the end.

The content of overall and elemental sulphur was investigated by elemental (CHNS) analysis and Soxhlet extraction, respectively (see Table I).

The overall sulphur content remained constant throughout milling, although some discrepancies were detected in the early stages. These are most probably due

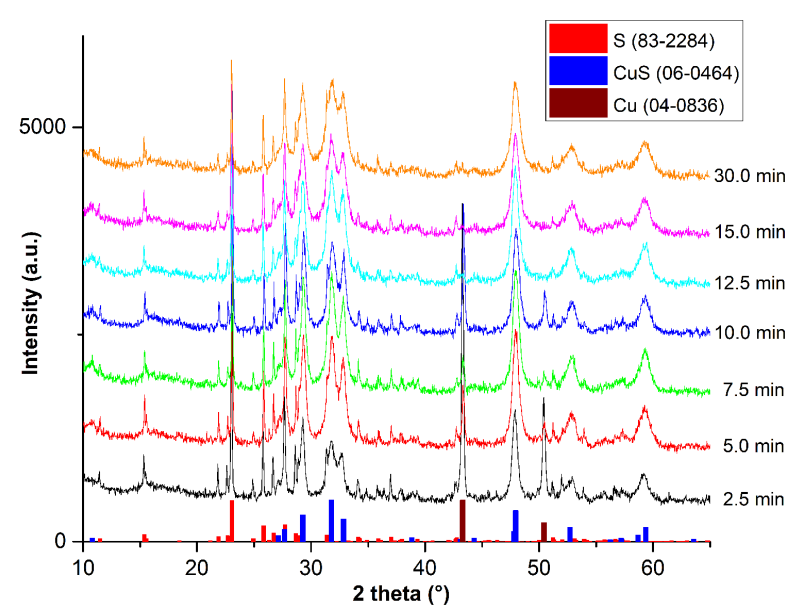

Fig. 1. XRD patterns of the powders milled for different times (time and identified phases are provided in the figure).

TABLE I

Overall and free sulphur content in the samples milled for different times

\begin{tabular}{c|c|c}
\hline \hline Time [min] & $\begin{array}{c}\text { Overall sulphur } \\
\text { content [\%] }\end{array}$ & $\begin{array}{c}\text { Free sulphur } \\
\text { content [\%] }\end{array}$ \\
\hline 2.5 & 45.2 & 31.2 \\
5 & 52.1 & 24.9 \\
7.5 & 52.0 & 23.1 \\
10 & 54.7 & 21.5 \\
12.5 & 50.7 & 23.6 \\
15 & 50.3 & 20.0 \\
30 & 50.7 & 18.7
\end{tabular}

to the inhomogeneous distribution of reactants. Especially at the very beginning (after $2.5 \mathrm{~min}$ ), sulphur as a lighter element was most probably present as a major substance in the powder on the lid, which resulted in its lower content in the analysed sample (45\%). However, the elements became homogeneously distributed within the milled powder with time.

The content of non-reacted sulphur decreased during the process. The decrease in the first stages of milling is more significant due to the progress of the $\mathrm{CuS}$ formation reaction. According to XRD (Fig. 1), this process seems to be finished after $12.5 \mathrm{~min}$. Upon the last $15 \mathrm{~min}$ of treatment, only a slight decrease of free $\mathrm{S}$ content was observed, which could be due to the measurement error. This means that it is no longer used for the reaction. Theoretically, the content of free sulphur should be $25 \%$ upon complete $\mathrm{CuS}$ formation, but sulfur is volatile and its fraction most probably ended up on the lid of the chamber at the beginning of the process and did not take part in the synthesis.

The magnetic response of the milled mixture was checked for each sample. The magnetization curves are presented in Fig. 2a and the maximum magnetization is plotted as a function of milling time in Fig. $2 \mathrm{~b}$. 


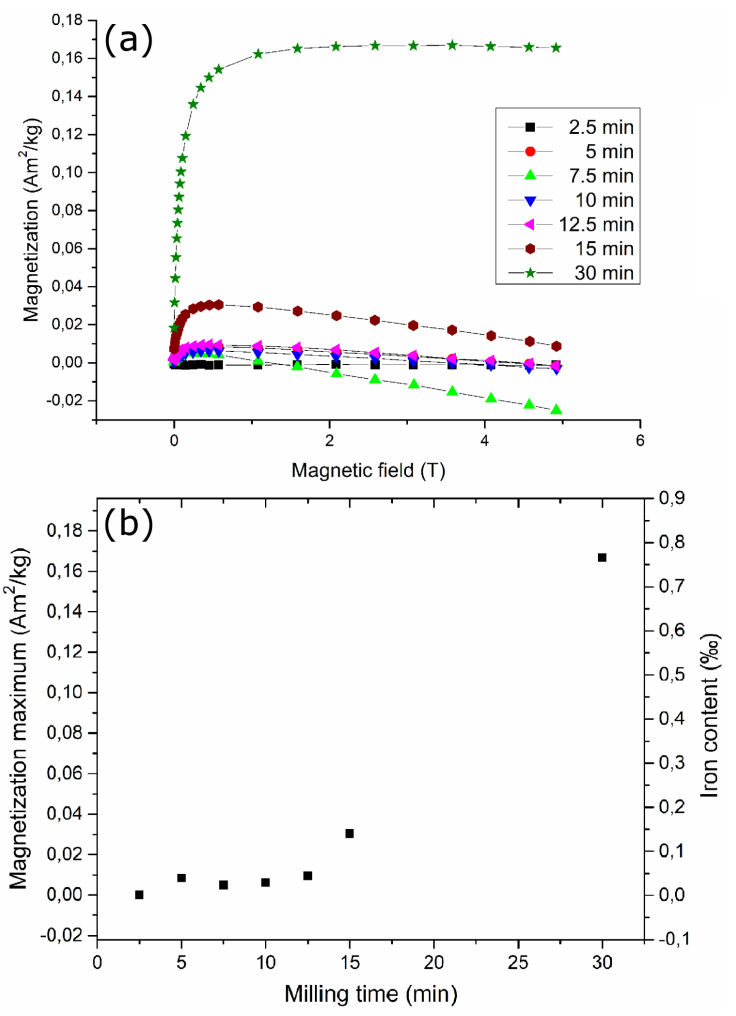

Fig. 2. Magnetometry results for the powders milled for different time (time of milling is given in the figure): (a) magnetization curves, (b) magnetization maximum and iron content vs. milling time.

The increase of magnetization value with milling time can be observed in Fig. 2a. As both reactants and products are diamagnetic, it can be only ascribed to the wear coming from the milling media, which is becoming larger when the duration of the process is increased. Most probably, small fragments are being torn down from the milling chamber walls and balls. This is evidenced by a sensitive magnetometer device as the negative diamagnetic signal is gradually suppressed by the emerging positive ferromagnetic contribution.

In order to quantify the wear, we assumed that no other component contributes to the magnetic signal. Using this assumption and the fact that the saturation magnetization value of pure iron is $216 \mathrm{~A} \mathrm{~m}^{2} / \mathrm{kg}$, the content of iron in the samples can be calculated. It can be seen that even ten-thousandths of per mille can be detected (for the sample treated for $2.5 \mathrm{~min}$ the value $6.77 \times 10^{-4 \%} \%$ was evidenced), which demonstrates the great sensitivity of this method. After the $\mathrm{CuS}$ formation is finished, the production of wear seems to increase significantly (from $0.13 \%$ o to $0.76 \%$ o for the powder treated for 15 and $30 \mathrm{~min}$, respectively). It seems that during the $\mathrm{CuS}$ formation, the energy is spent mostly on this process. However, after its completion, the presence of a significant amount of more refractory $\mathrm{CuS}$ material boosts the wear production by its collisions with the balls and chamber walls.

\section{Conclusions}

Magnetometry has been successfully used for the evaluation of trace amount of iron wear in the mechanochemical synthesis. As a model system, the reaction between diamagnetic copper and sulphur was selected. The reaction resulted in the formation of $\mathrm{CuS} / \mathrm{S}$ composite. This study shows the possibility for mechanochemists to use magnetometry as a universal effective method for the evaluation of trace amount wear and thus could help them to prevent undesirable problems upon further applications of the material.

\section{Acknowledgments}

The present study was financially supported by the Slovak Research and Development Agency under contract No. APVV-18-0357 and APVV-18-0160, Slovak Grant Agency VEGA (project 2/0044/18), and by the Ministry of Education and Science of Kazakhstan Republic (grants No. BR05234566 and AP05133115).

\section{References}

[1] P. Baláž, M. Achimovičová, M. Baláž et al., Chem. Soc. Rev. 42, 7571 (2013).

[2] G. Gonzalez, A. Sagarzazu, R. Villalba, J. Ochoa, L. D'Onofrio, Mater. Sci. Forum 360, 355 (2001).

[3] D. Margetic, V. Štrukil, Contamination from Wear in Organic Mechanosynthesis. Mechanochemical Organic Synthesis, Elsevier, Amsterdam 2016, p. 18.

[4] G. Stefanic, S. Krehula, I. Stefanic, Chem. Commun. 49, 9245 (2013).

[5] F.K. Urakaev, V.S. Shevchenko, KONA 25, 162 (2007).

[6] P. Baláž, E. Dutková, I. Škorvánek, E. Gock, J. Kováč, A. Šatka, J. Alloys Compd. 483, 484 (2009).

[7] P. Roy, S.K. Srivastava, Cryst. Eng. Commun. 17, 7801 (2015).

[8] D. He, P. Xue, D. Song, J. Qu, Z. Chao Laia, J. Electrochem. Soc. 164, A1499 (2017).

[9] N. Karikalan, R. Karthik, S.M. Chen, C. Karuppiah, A. Elangovan, Sci. Rep. 7, (2017).

[10] M. Wild, G.J. Offer, L. O'Neill, T. Zhang, R. Purkayastha, G. Minton, M. Marinescub, Energy Environm. Sci. 8, 3477 (2015).

[11] M. Baláž, A. Zorkovská, F. Urakaev, P. Baláž, J. Briančin, Z. Bujňáková, M. Achimovičová, E. Gock, $R S C$ Adv. 6, 87836 (2016). 